\title{
PENGARUH MODEL PEMBELAJARAN SELF-DIRECTED LEARNING TERHADAP PENINGKATAN KUALITAS PERKULIAHAN FISIOLOGI TUMBUHAN DI PROGRAM STUDI PENDIDIKAN BIOLOGI STKIP RIAMA MEDAN
}

\section{OLEH:}

\author{
JIMMY FRANCIUS SIMBOLON \\ (STKIP RIAMA MEDAN)
}

\begin{abstract}
This research aims to determine the effect of the Self Directed Learning (SDL) model on improving the quality of plant physiology lectures in the Biology Education Study Program STKIP Riama Medan. The populationsare students of Biology Education Study Program TA. 2013/2014 which is 20 people. The sample of the research were all members of the population in this research. The method used in this research is descriptive method with purposive sampling technique. Based on the results of the study, it is known that students have applied the Self Directed Learning (SDL) learning model with high (63\%). Learning evaluation results also increased by $15 \%$ from $60 \%$ to $75 \%$. Self Directed Learning (SDL) model is very influential on improving the quality of Plant Physiology lectures in Biology Education Study Program STKIP Riama Medan.
\end{abstract}

Keywords: Self Directed Learning (SDL), plant physiology

\section{PENDAHULUAN}

\section{Latar Belakang}

Mata kuliah Fisiologi Tumbuhan adalah salah satu Mata Kuliah Keahlian dan Keterampilan (MKK) yang ditawarkan pada Program StudiS1 Pendidikan Biologi STKIP Riama Medan. Mata kuliah ini terdiri dari 2 sks teori dan 1 sks praktikum. Mata kuliah inibertujuan agar mahasiswa mengetahui dasar-dasar ilmu Fisiologi Tumbuhan, menjelaskan dan menerapkan ilmu Fisiologi Tumbuhan dalam kehidupan bermasyarakat. Dalam kurikulum, mata kuliah ini diambil pada semester 4 dengan prasyarat Biokimia. 
Pelaksanaan mata kuliah Fisiologi Tumbuhan terintegrasi antara teori dan praktik sehingga kemampuan dan hasil belajar mahasiswa ditentukan secara utuh meliputi ranah kognitif, afektif, dan psikomotor. Materi kuliah Fisiologi Tumbuhan meliputi: Respirasi; Hormon; Perkecambahan; Dormansi; Pertumbuhan; Gerak Tumbuhan; Perkembangan; Fotoperiodisme. (SAP Fisiologi Tumbuhan, 2014).

Setiap mata kuliah memiliki tantangan dan kesulitan tersendiri bagi mahasiswa maupun dosen pengampu, termasuk mata kuliah fisiologi tumbuhan. Tantangan yang dihadapi yaitu membuat mahasiswa mampu memahami proses aktivitas tumbuhan dan mengaitkannya secara kontekstual. Kesulitan yang sering penelitihadapi sebagai dosen pengampu adalah bagaimanamembuat mahasiswa menikmati pembelajaran, menguasai pengetahuansekaligus keterampilan dalam melaksanakanpenelitian dasar pada praktikum. Kesulitan bagi mahasiswa karena materi Fisiologi Tumbuhan keseluruhan menjelaskan proses-proses aktivitas kehidupan tumbuhan secara fisika, kimiawi, dan biologis yangtidak berhubunganlangsung dengan mahasiswa sehingga mata kuliah ini menjadi kurang menarik. Mahasiswa harus menguasai fisika dan kimia. Tentu bagi mahasiswa biologi hal ini memberikan kesulitan tersendiri yang mempengaruhi kualitas perkuliahan.

Selama ini pendekatan pembelajaran yang dilakukan merupakan Teacher Centered Learning (TCL) dengan metode pembelajaran lebih banyak didominasi oleh ceramah. Nilai akhir mahasiswa pada TA. 2012/2013 yaitu 12 orang (60\%) A; 6 orang $(30 \%) \mathrm{B}$; dan 2 orang $(10 \%)$ C. Oleh karena itu penulis menganggap 
perlu merancang pendekatan, strategi, metode ataupun model pembelajaran agar dapat mengatasi kesulitan yang dihadapi mahasiswa dalam pembelajaran sehingga mahasiswa tidak pasif dan bosan. Rancangan pembelajaran tersebut harus sedemikian rupa menempatkan mahasiswa sebagai pusat pembelajar.

Pendekatanpembelajaran yang dapat dipakai adalah Student Centered Learning (SCL).SCL (Student Centered Learning) merupakan pendekatan pembelajaran yangmemberdayakan peserta didik menjadi pusat perhatian selama prosespembelajaran berlangsung. (Dikti, 2014). SCL merupakan pendekatan pembelajaran yang menempatkan mahasiswa sebagai subyek/peserta didik yang aktif dan mandiri, dengan kondisi psikologik sebagai adult learner, bertanggung jawab sepenuhnya atas pembelajarannya, serta mampu belajar beyond the classroom. Dengan prinsip-prinsip ini maka para mahasiswa diharapkan memiliki dan menghayati jiwa life-long learner serta menguasai hard skills dan soft skillsyang saling mendukung. Di sisi lain, para dosen beralih fungsi menjadi fasilitator, termasuk sebagai mitra pembelajaran, tidak lagi sebagai sumber pengetahuan utama (Harsono, 2005).

Dibandingkan dengan pendekatan pembelajaran Teacher Centered Learning (TCL) yang berpusat pada Dosen sebagai sumber informasi, Student Centered Learning (SCL) membuat mahasiswa lebih memahami dan lebih spesifik tentang materi yang dipelajari, mendorong mahasiswa belajar lebih aktif, mandiri, sesuai dengan iramabelajarnya masing-masing, sesuai dengan perkembangan usia pesertadidik, irama belajar mahasiswa tersebut perlu dipandu agar terus dinamisdan mempunyai tingkat kompetensi yang tinggi (Dikti, 2014). 
Beberapa modelpembelajaran SCL menurut Dikti, 2014 adalah sebagai berikut:

\section{a. Small Group Discussion (SGD)}

Model pembelajaran yang melibatkanantara kelompok mahasiswa dan kelompok mahasiswa lain atau kelompokmahasiswa dan pengajar untuk menganalisa, menggali ataumemperdebatkan topik atau permasalahan tertentu.Dengan metode ini pengajar harus, (1) membuat rancangan bahandiskusi dan aturan diskusi. (2) menjadi moderator dan sekaligusmengulas pada setiap akhir sesi diskusi. Sedangkan mahasiswa (1)membentuk kelompok (5 -10) mahasiswa, (2) memilih bahan diskusi,(3) mempresentasikan paper dan mendiskusikannya di kelas.

\section{b. Role-Play and Simulation}

Model interaksi antara dua atau lebih mahasiswatentang suatu topik atau kegiatan dengan menampilkan simbol-simbolatau peralatan yang menggantikan proses, kejadian, atau sistem yangsebenarnya. Jadi dengan model ini mahasiswa mempelajari sesuatu(sistem) dengan menggunakan model. Dengan metode ini pengajarharus, (1) merancang situasi atau kegiatan yang mirip dengansesungguhnya, bisa berupa; bermain peran, model, dan komputer, (2)membahas kinerja mahasiswa. Sedangkan mahasiswa (1) mempelajaridan menjalankan suatu peran yang ditugaskan, (2) memperaktekanatau mencoba berbagai model yang telah disiapkan (komputer,prototipe, dll). 


\section{c. Discovery Learning}

Model pembelajaranberbentuk pemberian tugas belajar atau penelitian kepadamahasiswa dengan tujuan mahasiswa mencarijawaban tanpa bantuan pengajar.Dengan metode ini pengajar harus, (1) menyediakan data ataumetode untuk menelusuri pengetahuan yang akan dipelajarimahasiswa, (2) memeriksa dan memberikan ulasan terhadap hasilbelajar mahasiswa. Sedangkan mahasiswa (1) mencari,mengumpulkan, dan menyusun informasi yang ada untukmendeskripsikan suatu pengetahuan yang baru, (2) mempresentasikansecara verbal dan non verbal.

\section{d. Self-Directed Learning}

Model berbentuk pemberian tugas belajar kepada mahasiswa,seperti tugas membaca dan membuat ringkasan. Dengan metode inipengajar harus, (1) memotivasi dan memfasilitasi mahasiswa, (2)memberikan arahan, bimbingan dan umpan balik kemajuan belajarmahasiswa. Sedangkan mahasiswa merencanakan kegiatan belajar,melaksanakan, dan menilai pengalaman belajar sendiri, (2) inisiatifbelajar dari mahasiswa sendiri.

\section{e. Cooperative Learning}

Model pembelajaran dengan cara berkelompok untuk bekerja sama saling membantumengkontruksi konsep, menyelesaikan persoalan, atau inkuiri.Tiap kelompok terdiri dari 4 - 5 orang, mahasiswaheterogen (kemampuan, gender, karekter), ada kontrol dan fasilitasi,dan meminta tanggung jawab hasil kelompok berupa laporan ataupresentasi. Sintaks pembelajaran koperatif adalah informasi,pengarahan-strategi, membentuk kelompok heterogen, kerja 
kelompok,presentasi hasil kelompok, dan pelaporan.Dengan metode ini pengajar harus, (1) merancang dan memonitorproses belajar mahasiswa, (2) menyiapkan kasus atau masalah untukdiselesaikan mahasiswa secara berkelompok. Sedangkan mahasiswa(1) membahas dan menyimpulkan masalah atau tugas yang diberikansecara berkelompok (2) melakukan koordinasi dalam kelompok.

\section{f. Contextual Learning $(C L)$}

Model pembelajaran dimulaidengan sajian atau tanya jawab lisan yangterkait dengan dunia nyata kehidupan mahasiswa (daily life modeling),sehingga akan terasa manfaat dari materi yang akan disajikan, motivasibelajar muncul, dunia pikiran mahasiswa menjadi konkret, dan suasanamenjadi kondusif, nyaman dan menyenangkan. Prinsip pembelajarankontekstual adalah aktivitas mahasiswa, mahasiswa melakukan danmengalami, tidak hanya menonton dan mencatat, dan pengembangankemampuan sosialisasi. Tujuh indikator pembelajaran kontekstual yaitu modelling, questioning, learning community, inquiry, constructivism,reflection, dan authentic assessment.Dengan metode ini pengajar harus, (1) menyusun tugas untuk studimahasiswa di lapangan, (2) menjelaskan bahan kajian yangbersifat teori dan mengkaitkan dengan situasi nyata atau kerjaprofesional. Sedangkan mahasiswa (1) melakukan studi lapangan atauterjun di dunia nyata untuk mempelajari kesesuaian teori (2)membahas konsep atau teori yang berkaitan dengan situasi nyata. 


\section{g. Problem Based Learning (PBL)}

Modelpembelajaran ini melatih dan mengembangkan kemampuan menyelesaikan masalah yang berorientasi pada masalah otentik darikehidupan aktual mahasiswa, merangsang kemampuan berpikirtingkat tinggi (HOTS). Dengan metode inipengajar harus, (1) merangsang tugas belajar dengan berbagaialternatif metode penyelesaian masalah (2) sebagai fasilitator danmotivator. Sedangkan mahasiswa (1) belajar dengan menggali ataumencari informasi (inquiry), serta memamfaatkan informasi tersebutuntuk memecahkan masalah faktual yang sedang dihadapi, (2)menganalisis strategi pemecahan masalah.

\section{h. Collaborative Learning ( $C b L)$}

Model pembelajaranbertujuan mencari danmenemukan jawaban sebanyak mungkin, saling berinteraksi untukmenggali semua kemungkinan yang ada.Dengan metode ini pengajar harus, (1) Merancang tugas yangbersifat open ended, (2) Sebagai fasilitator dan motivator. Sedangkanmahasiswa (1) Membuat rancangan proses dan bentuk penilaianberdasarkan konsensus kelompok sendiri (2) Bekerja sama dengananggota kelompoknya dalam mengerjakan tugas.

\section{i. $\quad$ Project Based Learning (PjBL)}

Model pembelajaran ini memberikan tugas-tugas projectyang harus diselesaikan oleh mahasiswa dengan mencari sumberpustaka sendiri. Dengan metode ini pengajar harus, (1) merumuskantugas dan melakukan proses pembimbingan dan asesmen, (2) sebagaifasilitator dan motivator. Sedangkan mahasiswa (1) mengerjakan tugas(berupa proyek) yang telah dirancang secara 
sistematis (2) menunjukkankinerja dan mempertanggungjawabkan hasil kerja di forum.

Berdasarkan latar belakang masalah di atas maka peneliti menganggap perlu melakukan penelitian tentang pengaruh model pembelajaran Self Directed Learning (SDL) terhadap peningkatan kualitas perkuliahan fisiologi tumbuhan dengandi Program Studi Pendidikan Biologi STKIP Riama Medan.

\section{Identifikasi Masalah}

Dalam penelitian ini yang menjadi identifikasi masalah adalah bagaimana pengaruh model pembelajaran Self Directed Learning (SDL) terhadap peningkatan kualitas perkuliahan fisiologi tumbuhan dengan di Program Studi Pendidikan Biologi STKIP Riama Medan.

\section{Batasan Masalah}

Masalah dalam penelitian ini dibatasi pada 5 aspek penilaian yaitu kesadaran, strategi belajar, aktivitas pembelajaran, evaluasi dan kemampuan interpersonal. Peningkatan kualitas perkuliahan yang dimaksud adalah nilai akhir atau hasil belajar mahasiswa dalam mata kuliah Fisiologi Tumbuhan.

\section{Perumusan Masalah}

Yang menjadi perumusan masalah dalam penelitian ini adalah:Bagaimana pengaruh model pembelajaran Self Directed Learning (SDL) terhadap peningkatan kualitas perkuliahan fisiologi tumbuhan dengan di Program Studi Pendidikan Biologi STKIP Riama Medan? 


\section{Tujuan Penelitian}

Yang menjadi tujuan dalam penelitian ini adalah:Untuk mengetahuipengaruh model pembelajaran Self Directed Learning (SDL) terhadap peningkatan kualitas perkuliahan fisiologi tumbuhan dengan di Program Studi Pendidikan Biologi STKIP Riama Medan.

\section{METODE PENELITIAN}

\section{Lokasi dan Waktu Penelitian}

Penelitian dilaksanakan di Program Studi Pendidikan Biologi STKIP Riama Medan Jln Tritura No. 6 Medan pada semester genap Tahun Akademik 2013/2014. Waktu penelitian pada bulan Pebruari 2014.

\section{Populasi dan Sampel dan Sampling}

Populasi penelitian adalah mahasiswa Program Studi Pendidikan Biologi STKIP Riama Medan. Sampel penelitian adalah mahasiswa semester IVTahun Akademik 2013/2014 yang berjumlah 20 orang.

Sampling dalam penelitian ini memakai teknik purposive sampling. Pada tehnik ini, ditentukan sampel dengan pertimbangan tertentu yaitu mahasiswa yang sedang mengambil mata kuliah Fisiologi Tumbuhan.

\section{Jenis Penelitian}

Jenis penelitian yang digunakan dalam penelitian ini adalah penelitian kuantitatif dengan metode penelitian deskriptif. Penelitian deskriptif berfungsi untuk mendeskripsikan atau memberi gambaran terhadap obyek yang diteliti 
melalui data atau sampel yang telah terkumpul sebagaimana adanya, tanpa melakukan analisis dan membuat kesimpulan yang umum (Sugiyono, 2011).

\section{Data dan Sumber Data}

a) Data

Jenis data yang digunakan dalam penelitian ini adalah data kuantitatif berupa jumlah mahasiswa dan hasil angket. Data kuantitatif adalah jenis data yang dapat diukur atau dihitung secara langsung, yang berupa informasi atau penjelasan yang dinyatakan dengan bilangan atau berbentuk angka (Sugiyono, 2011).

b) Sumber Data

Penelitian ini menggunakan satu sumber data yaitu sumber data primer yang dikumpulkan oleh peneliti dari sumber pertama yaitu mahasiswa Prodi Pendidikan Biologi semester IV yang sedang mengambil mata kuliah Fisiologi Tumbuhan.

\section{Teknik Pengumpulan Data}

Dalam penelitian ini penulis memberikan angket kepada mahasiswa Prodi Pendidikan Biologi semester IV yang sedang mengambil mata kuliah Fisiologi Tumbuhan. Data diukur dengan skala likert dengan rentang nilai 1-5, yaitu 1 = Sangat Tidak Setuju, $2=$ Tidak Setuju, 3 = Ragu-ragu, $4=$ Setuju, dan 5 $=$ Sangat Setuju

\section{Tehnik Analisis Data}

Analisis deskriptif merupakan kegiatan mengumpulkan, mengolah, dan mendeskripsikan data yang terkumpul (Sugiyono, 2011). Datahasil angket 
tentang5 aspek penilaian dalamSelf Directed Learning (SDL) yaitu kesadaran, strategi belajar, aktivitas pembelajaran, evaluasi dan kemampuan interpersonal. Analisis ini dikelompokkan berdasarkan jawaban yang sama, kemudian dipersentasekan berdasarkan jumlah responden.

\section{HASIL PENELITIAN}

Hasil angketpengaruh model pembelajaran Self Directed Learning (SDL) terhadap kualitas perkuliahan mata kuliahFisiologi Tumbuhan disajikan pada tabel di bawah ini.

\begin{tabular}{llccc}
\hline \multirow{2}{*}{ No. } & \multicolumn{1}{c}{ Aspek } & \multicolumn{3}{c}{ Kategori dan Persentase Skor } \\
\cline { 3 - 5 } & & $\begin{array}{c}12-28 \\
\text { (Rendah) }\end{array}$ & $\begin{array}{c}29-44 \\
(\text { Sedang) }\end{array}$ & $\begin{array}{c}45-60 \\
(\text { Tinggi) }\end{array}$ \\
\hline 1. & Kesadaran & $0 \%$ & $20 \%$ & $80 \%$ \\
2. & Strategi Belajar & $0 \%$ & $30 \%$ & $70 \%$ \\
3. & Aktivitas Pembelajaran & $0 \%$ & $50 \%$ & $50 \%$ \\
4. & Evaluasi & $0 \%$ & $45 \%$ & $55 \%$ \\
5. & Kemampuan Interpersonal & $0 \%$ & $40 \%$ & $60 \%$ \\
\hline & Rata-rata (\%) & $\mathbf{0 \%}$ & $\mathbf{3 7 \%}$ & $\mathbf{6 3 \%}$ \\
\hline
\end{tabular}

Berdasarkan tabel di atas dapat diketahui bahwa pada aspek kesadaran, sebanyak 4 orang (20\%) berada pada kategori sedang, dan 16 orang $(80 \%)$ berada pada kategori tinggi. Pada aspek strategi belajar, sebanyak 6 orang (30\%) berada pada kategori sedang, dan 14 orang (70\%) berada pada kategori tinggi. Pada aspek aktivitas pembelajaran, sebanyak 10 orang $(50 \%)$ berada pada kategori sedang, dan 10 orang (50\%) berada pada kategori tinggi. Pada aspek evaluasi, sebanyak 9 orang $(45 \%)$ berada pada kategori sedang, dan 11 orang $(55 \%)$ berada pada kategori tinggi. Dan pada aspek kemampuan interpersonal, sebanyak 8 orang 
(40\%) berada pada kategori sedang, dan 12 orang (60\%) berada pada kategori tinggi.

Gambaran aspek penilaian dalam Self Directed Learning (SDL) dapat dilihat pada diagram berikut:

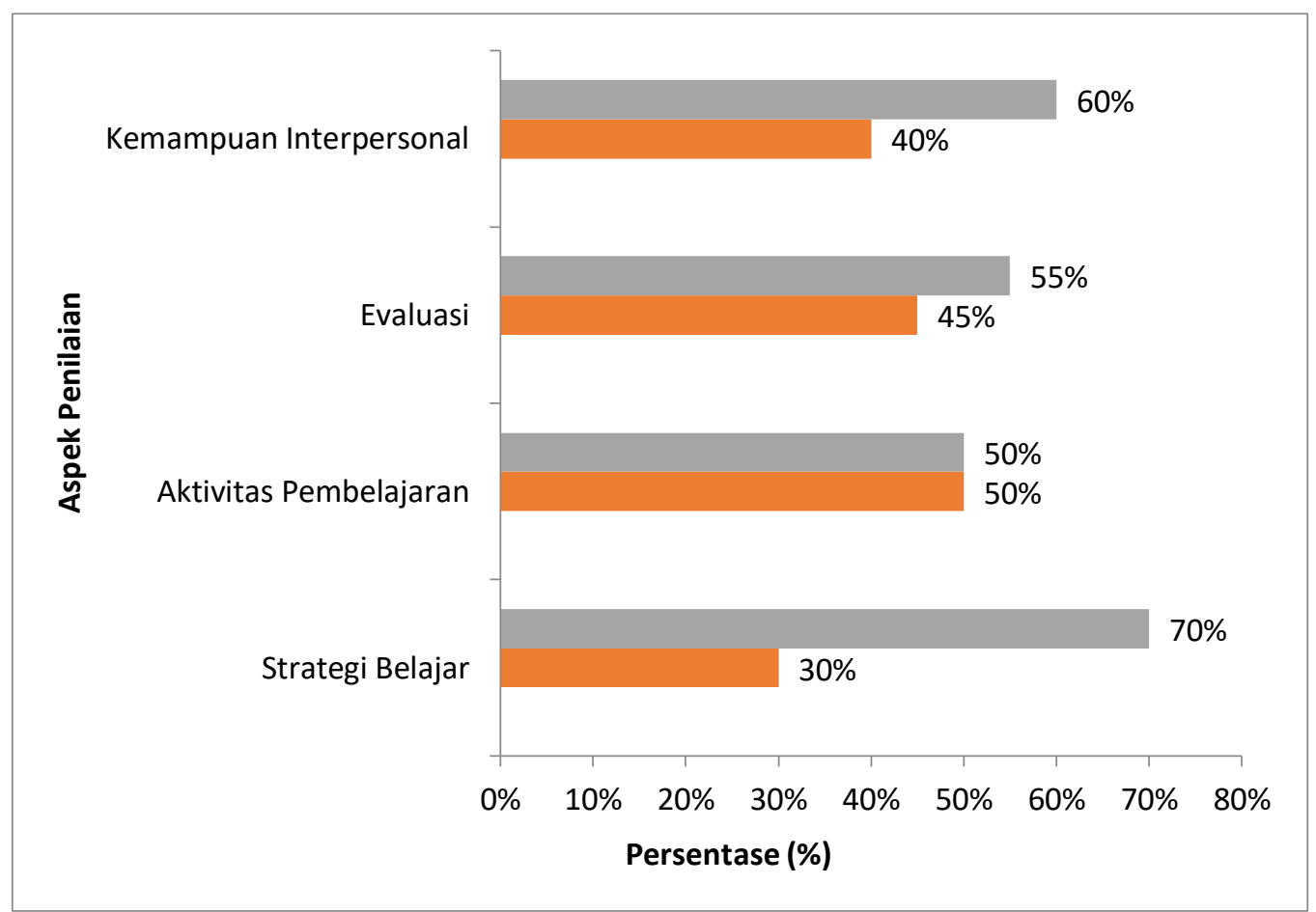

Jika keseluruhan aspek dirangkum maka akan diperoleh skor keseluruhan yang dapat dilihat pada tabel di bawah ini:

\begin{tabular}{cccl}
\hline No. $\begin{array}{c}\text { Kisaran } \\
\text { Skor }\end{array}$ & $\begin{array}{c}\text { Persentase } \\
(\%)\end{array}$ & Tingkat SDL & \multicolumn{2}{c}{ Interpretasi } \\
\hline & & & $\begin{array}{l}\text { Mahasiswa belum mampu } \\
\text { menjadi pembelajar mandiri. } \\
\text { Arahan dari dosen sangat } \\
\text { diperlukan. Perubahan spesifik } \\
\text { apapun diperlukan untuk } \\
\text { perbaikan dalam metode } \\
\text { pembelajaran. }\end{array}$ \\
\hline
\end{tabular}




\begin{tabular}{|c|c|c|c|c|}
\hline .2 & $141-220$ & $37 \%$ & Sedang & $\begin{array}{l}\text { Belajar mandiri } \text { cukup } \\
\text { membantu mahasiswa menjadi } \\
\text { pembelajar mandiri. Namun } \\
\text { tetap perlu perbaikan. Evaluasi } \\
\text { dan strategi pembelajaran yang } \\
\text { digunakan memerlukan } \\
\text { pendampingan dari dosen. }\end{array}$ \\
\hline 3. & $221-300$ & $63 \%$ & Tinggi & $\begin{array}{l}\text { Mahasiswa berhasil menjadi } \\
\text { pembelajar mandiri. Setiap } \\
\text { aspek dalam pembelajaran } \\
\text { mandiri telah tercapai dengan } \\
\text { efektif. }\end{array}$ \\
\hline
\end{tabular}

Dari tabel di atas dapat diketahui bahwa secara keseluruhan, mahasiswa telah menerapkan model Self Directed Learning (SDL) dengan hasil tinggi (63\%) dan sedang (37\%). Dengan demikian model Self Directed Learning (SDL) telah dilaksanakan dengan baik.

Berdasarkan nilai yang diperoleh mahasiswa pada mata kuliah Fisiologi Tumbuhan TA. 2013/2014, dapat dilihat pada tabel berikut:

\begin{tabular}{cccc}
\hline No. & Rentang Nilai & Jumlah & Persentase (\%) \\
\hline .1. & A & 15 & $75 \%$ \\
2. & B & 5 & $25 \%$ \\
3. & C & 0 & $0 \%$ \\
4. & D & 0 & $0 \%$ \\
5. & E & 0 & $0 \%$ \\
\hline
\end{tabular}

Dari tabel di atas diketahui bahwa hasil belajar pada mata kuliah Fisiologi Tumbuhan mengalami peningkatan dari tahun sebelumnya. Dengan demikian diketahui bahwa model pembelajaran Self Directed Learning (SDL) sangat berpengaruh pada peningkatan kuallitas perkuliahan Fisiologi Tumbuhan di Prodi Pendidikan Biologi STKIP Riama Medan. 


\section{KESIMPULAN DAN SARAN}

\section{Kesimpulan}

Berdasarkan hasil penelitian dan pembahasan yang telah dikemukakan maka dapat disimpulkan bahwa:

1. Mahasiswa telah menerapkan model pembelajaran Self Directed Learning (SDL) dengan tinggi (63\%).

2. Hasil belajar mahasiswa mengalami peningkatan dari tahun sebelumnya, yaitu A (75\%) dan B (25\%).

3. Model pembelajaran Self Directed Learning (SDL) sangat berpengaruh terhadap peningkatan kuallitas perkuliahan Fisiologi Tumbuhan di Prodi Pendidikan Biologi STKIP Riama Medan.

\section{Saran}

Berdasarkan kesimpulan di atas maka peneliti memberikan saran sebagai berikut:

1. Dosen pengampu mata kuliah agar mengembangkan model pembelajaran Self Directed Learning (SDL) untuk meningkatkan kualitas perkuliahan.

2. Dosen pengampu mata kuliah agar merancang dan melaksanakan pembelajaran dengan metode dan model yang bervariasi agar mahasiswa menjadi lebih tertarik.

\section{DAFTAR PUSTAKA}

Dikti, 2014. Panduan Penyusunan Kurikulum Pendidikan Tinggi (K-DIKTI), Direktorat Jenderal Pendidikan Tinggi, Kementrian Pendidikan dan Kebudayaan.

Harsono, Dwiyanto D. 2005. Pembelajaran berpusat mahasiswa. Yogyakarta: Pusat Pengembangan Pendidikan Universitas Gadjah Mada, Aditya Media. 
Herawati, Susilo Balqis. 2014.Peningkatan Kualitas Perkuliahan Fisiologi Tumbuhan Melalui LessonStudy Di Jurusan Biologi FMIPA UM. Malang: FMIPA Universitas Neegeri Malang.

Prodi Pendidikan Biologi. 2014. Satuan Acara Pengajaran (SAP). Medan: Sekolah Tinggi Keguruan dan Ilmu Pendidikan Riama.

Sugiyono, 2011. Metode Penelitian Kuantitatif, Kualitatif dan R\&D. Bandung: Alfabeta.

Reza Rindy Antika. 2014. Proses Pembelajaran Berbasis Student Centered Learning (Studi Deskriptif di Sekolah Menengah Pertama Islam Baitul 'Izzah, Nganjuk. Jurnal BioKultur, Vol.III/No.1/Januari-Juni 2014.

Riri Wardita Sari S. 2019. Pengaruh SDL (Self Directed Learning) Terhadap Nilai Evaluasi Belajar Mahasiswa Program Studi Kedokteran UMY. Yogyakarta: Universitas Muhammadiyah Yogyakarta. 